\begin{tabular}{|c|l|}
\hline Title & Strain distribution in asphalt mixtures during the wheel tracking test at high temperatures \\
\hline Author(s) & Moriyoshi, A kihiro; Takahashi, Naoy uki; Ikeda, Osamu; Kawashima, Masato; A kabane, Takahiko \\
\hline Citation & $\begin{array}{l}\text { Construction and Building Materials, 40, 1128_1135 } \\
\text { https://doi.org/40.1016/.Conbuildmat.2012.11.040 }\end{array}$ \\
\hline Issue Date & 201303 \\
\hline Doc URL & http://hdl.handle.net/2115/52247 \\
\hline Type & article (author version) \\
\hline File Information & CBM40_951.pdf \\
\hline
\end{tabular}

Instructions for use 


\section{[Research Paper]}

Strain distribution in asphalt mixtures during the wheel tracking test at high temperatures

Akihiro Moriyoshi $^{\mathrm{a}, 1, *}$, Naoyuki Takahashi ${ }^{\mathrm{b}}$, Osamu Ikeda ${ }^{\mathrm{c}}$, Masato Kawashima ${ }^{\mathrm{d}}$, Takahiko Akabane ${ }^{\mathrm{e}}$

Word count:22326 words plus 6 Tables and 6 Figures

a,1,* Akihiro Moriyoshi

Division of Urban and Environmental Engineering, Graduate School of Engineering, Hokkaido University, North 13 West 8, Kita-ku, Sapporo, 060-8628, JAPAN

Current affiliation and address:

Material Science Laboratory

Hokkaido University Emeritus Professor

2-1-9-10 Kiyota, Kiyota-ku, Sapporo, 004-0842, JAPAN

Phone/Fax: +81-11-882-4246, E-mail: moriyoshi@cap.ocn.ne.jp

${ }^{\mathrm{b}}$ Naoyuki Takahashi

East Nippon Expressway Ltd., Hokkaido Branch,

12-30, West 5, Ooyachi, Atsubetsu-ku, Sapporo, 004-8512, JAPAN

Current affiliation and address: 
East Nippon Expressway Ltd., Chitose Construction Office

1-2-14, Shintomi, Chitose, Hokkaido, 066-0037, JAPAN

Phone: +81-123-22-9882, Fax: +81-123-22-0384, E-mail:

n.takahashi.ac@e-nexco.co.jp

${ }^{\mathrm{c}}$ Osamu Ikeda

East Nippon Expressway Ltd., Hokkaido Branch,

12-30, West 5, Ooyachi, Atsubetsu-ku, Sapporo, 004-8512, JAPAN

Current affiliation and address:

East Nippon Expressway Ltd., Hokkaido Branch,

12-30, West 5, Ooyachi, Atsubetsu-ku, Sapporo, 004-8512, JAPAN

Phone: +81-11-896-5814, Fax: +81-11-896-5200,

E-mail:o.ikeda.aa@e-nexco.co.jp

${ }^{\mathrm{d}}$ Masato Kawashima

East Nippon Expressway Ltd., Hokkaido Branch,

12-30, West 5, Ooyachi, Atsubetsu-ku, Sapporo, 004-8512, JAPAN

Current affiliation and address:

East Nippon Expressway Ltd., Hokkaido Branch,

12-30, West 5, Ooyachi, Atsubetsu-ku, Sapporo, 004-8512, JAPAN

Phone: +81-11-896-5322, Fax: +81-11-896-5885, 
E-mail:m.kawashima.ab@e-nexco.co.jp

${ }^{\mathrm{e}}$ Takahiko Akabane

Marubeni Information Systems Ltd.,

Shibuya Tokyu Building, 3-12-18 Shibuya, Shibuya-ku, Tokyo, 150-0002, JAPAN, Current affiliation and address:

Marubeni Information Systems Ltd.,

Shibuya Tokyu Building, 3-12-18 Shibuya, Shibuya-ku, Tokyo, 150-0002, JAPAN, Phone: +81-3-5778-8043, Fax: +81-3-578-8909,

E-mail: Akabane-Takahiko@marubeni-sys.com

* Corresponding author: Akihiro Moriyoshi

Present address:

${ }^{1}$ Material Science Laboratory

Hokkaido University Emeritus Professor

2-1-9-10 Kiyota, Kiyota-ku, Sapporo, 004-0842, JAPAN

Phone/Fax:+81-11-882-4246, E-mail: moriyoshi@cap.ocn.ne.jp

Keywords: Asphalt mixture, Wheel tracking test, High temperature, Evaluation, Tensile strain, Shear stain, Micro-focus computerized tomography (CT) scanner, ARAMIS System 


\section{Introduction}

When vehicles pass across asphalt pavements at high temperatures, rutting is observed on the surface of the pavement. Recently, the rutting of pavements using modified asphalt has decreased, but longitudinal cracks are frequently observed in asphalt pavements at high temperatures in Japan. Many longitudinal cracks occur even at the center of traffic lanes outside the areas where the wheels of moving vehicles directly contact the asphalt pavement. The causes of the longitudinal cracks have not been fully elucidated.

Much research has considered the longitudinal crack to be caused by shear stresses arising from the moving vehicles at high temperatures [1-5]. It was supposed that those cracks may be occurred by large strains for short periods at the asphalt mortar in mixture under the wheel of the passing vehicles, when they exceed critical strain values [6]. This paper examines where in the asphalt the cracks arise using two methods. One method is to measure the tensile strain and shear strain in mixtures. The value, the position, and the direction of the those strains were measured which arises around aggregate in asphalt mixtures under wheel tracking test (TRRL Type) at high temperatures for three types of asphalt compositions, using the ARAMIS system (GOM MbH., Germany). Other method is to measure a three dimensional crack in mixtures using CT scanner (Shimazu Corporation, inspeXio SMX-22CT) and soft ware (ExFact Analysis 2.0 for Porous/Particles, NVS LtD.) for small specimens after wheel tracking test. 
The results show that tensile strain and shear strain were accumulated under repeated loading at high temperatures and the cracks in the asphalt mixtures were caused by accumulated strains which exceed specific values. The cracks were mainly caused by tensile strain rather than shear strain.

This paper shows ARAMIS system and three dimensional crack analyses were very useful to measure the strains and cracks in mixtures under wheel tracking test at high temperatures and the quality of asphalt mixtures can be evaluated by those methods..

\section{Experiments and methods}

\subsection{Materials}

\subsubsection{Asphalt}

The characteristics of the asphalts, which were used in this study, are shown in Table 1.

Type kai asphalt (Type kai) is a modified Type that is commonly used in Japan. Asphalts No.3 and No.5 are high viscosity asphalts, according to the Kyoto specifications as detailed below [7].

\subsubsection{Composition of mixtures}

Four types of aggregate mixture compositions were used in this study: a gap type coarse mixture with an upper limit in the grading curve (Upper: SGU), a gap type coarse mixture with a mean limit in the grading curve (Middle: SGC), a gap type 
coarse mixture with a lower limit in the grading curve (Lower: SGL), and a hybrid type (K II , a hybrid type mixture of porous asphalt and dense graded type mixture) in Table 2. The void ratio of mixtures in this study was shown in Table 3.

\subsection{Methods}

\subsubsection{Wheel tracking tests (Hokkaido University Type)}

Wheel tracking test of Hokkaido University Type was used in this study. The outline of this test, test conditions, and the method how to make the specimen are as follows.

The specimens $(5 \times 30 \times 30 \mathrm{~cm})$ in this test were made according to the specifications of a pavement manual [8] commonly used in Japan, and the wheel tracking test of Hokkaido University Type [9] is the same type of Road Research Laboratory in UK, but the one end provided with transparent glass. Mixtures were compacted by the same type of roller compactor in Road Research Laboratory. The rutting depth in mixtures under following conditions at 2,400 passes was $1 \mathrm{~mm}$ or smaller for all compositions in this study.

Contact pressure of wheel: $0.54 \mathrm{MPa}\left(5.5 \mathrm{~kg} / \mathrm{cm}^{2}\right)$

Width of solid rubber tire: $5 \mathrm{~cm}$

Moving speed of wheel: 42 passes/minute, Test temperature in room: $45 \mathrm{C}$

Steel frame for holding specimen: One end provided with transparent glass 
The nearest distance of wheel path: It is located $5 \mathrm{~mm}$ apart from the glass

Side conditions of specimen: Three sides were covered by insulating layer $(3 \mathrm{~cm})$ and steel frame.

Asphalt specimens $(5 \times 30 \times 30 \mathrm{~cm})$ were cut $3 \mathrm{~cm}$ from the end of the specimen with a diamond cutter to measure the strains. The specimen was placed in the holder with the cut surface facing the transparent glass.

Method of Photography: Two CCD cameras were set at angle in front (glass side of specimen) of the samples and photographed the end of the specimen using the two cameras simultaneously.

The timing of photographs (pass number of the wheel and the stage number) for an experiment with a total of 2,400 passes of the wheel (10 Stages) was at: 0 passes (0 Stage), after the first pass (1 Stage), at 50 passes (2), 100 passes (3), 200 passes (4), 400 passes (5), 600 passes (6), 1,200 passes (7), 1,800 passes (8), and at 2,400 passes (9).

\subsubsection{ARAMIS System}

\subsubsection{Details and Principles of the ARAMIS System}

The ARAMIS System is an optical system for measurement of 3D deformation and strain [10]. Precision of this system (strain: $0.01 \%$ ) had been confirmed by gauge. This system uses two cameras taking photographs with so-called digital image correlation (DIC). In this case, the cut end $(5 \times 30 \mathrm{~cm})$ of the specimens was sprayed 
with white and black in a random pattern. The ARAMIS sensor using a stereo method and DIC analysis of the random pattern (dot diameters: $1 \mathrm{~mm}$ or smaller) are enables to determine the 3D strain and the 3D displacements on the surface of the specimen.

It can measure the deformation in the blink of an eye for the end section of asphalt mixture under wheel tracking test at high temperature using CCD camera. Thereafter, the strains and the direction of strains were analyzed by ARAMIS system.

\subsubsection{ARAMIS Analysis}

The sprayed markers (diameter: $1 \mathrm{~mm}$ or smaller) and points at the four corners of the steel frame holding the specimen were used as standard points to measure the deformation and strains across the specimen. The images of photographs for end of the specimens (50 x $300 \mathrm{~mm}$ ) were divided into about 2,400 facets (one square of facet : $25 \times 25$ pixels, $6 \mathrm{~mm}^{2} /$ facet). The resolution of CCD camera was $5 \mathrm{M}$ pixels $=2448 \mathrm{x}$ 2050 pixels. The value for the changes in positions of the four corners of the facets and the centers of the facets between images of photographs (taken after different pass numbers) were measured. The direction of the shear angle of facets (shear in the following) and tensile strain of the facet was obtained using the difference from the initial position (initial coordinate) and the deformation gradient tensor [10].

The value of the shear (in degrees) was expressed with the inclination angle of facet between the initial position and that at some later stage in the experiment. The shear strain was obtained as the tangent value (tan) of the angle (between the initial 
position and the later ones). The values of the various parameters determined here (tensile strain, shear strain and others) determined for an each facet, the direction of the strain, and the angle (shear) were quantified and visualized in colors. This arrangement allows the measurement of a local value and an overall value for the tensile strain and shear strain of a specimen. Average and maximum values of the tensile strain and shear strain were also calculated by soft ware of ARAMIS system.

The tensile strain and shear strain in 2D are mainly examined in this study.

\section{Results and discussion}

\subsection{Tensile strain and shear strain at the end of a specimen}

\subsubsection{Relation between the strain in the specimens and longitudinal cracks}

The relationships between the tensile strains and the width of crack in mixtures using ARAMIS system and CT scanner were examined. The outline of three dimensional crack analyses and CT scanner in this study were as follows.

The whole specimen $(5 \times 30 \times 30 \mathrm{~cm})$ was cut after the wheel tracking test (2,400 passes) to obtain the specimen of CT scanner. A sample of CT scanner ( 2.5 x 5.0 x $8 \mathrm{~cm}$ ) was cut from the end of the specimen facing the glass, including the width of the wheel track $(5 \mathrm{~cm})$. The resulting image (3D image) obtained by the CT scanner (Shimazu Corporation, inspeXio SMX-22CT, 16 bit grey scales, 512 x 512 pixels, 1,440 sheets, size of pixel: $0.06 \times 0.06 \times 0.06 \mathrm{~mm}$ ) was analyzed by software (ExFact Analysis 2.0 for Porous/Particles, NVS LtD., Minimum crack width: $0.185 \mathrm{~mm}$ ) as detailed elsewhere [11]. The crack width was divided into seven colors such as red, 
orange, yellow, green, blue, indigo and purple. The precision of three dimensional analyses was confirmed with the artificial crack of $0.6 \mathrm{~mm}$ by researchers [11] and the many cracks in mixture at $45 \mathrm{C}$ under the same test conditions for various mixtures were also found using CT scanner [12]. It was confirmed that many cracks were also occurred in samples taken from the asphalt pavement in service [13].

Fig.1a. and Fig.1b. in Fig.1. show the 3D images obtained from the three dimensional crack analyses and ARAMIS system in specimen of SGL-3. The minimum crack width was $0.185 \mathrm{~mm}$ (red), and maximum crack width was $1.295 \mathrm{~mm}$ (purple) in this specimen (SGL-3) at 2,400 passes in Fig. 1a. and Fig. 1b.. The longitudinal black bar at the left side of the image in Fig.1a., Fig.1c. and Fig. 1d. were expressed the wheel $(5 \mathrm{~cm})$.

Fig. 1a. shows the cracks in 3D image of CT scanner for side $(5 \times 8 \mathrm{~cm})$ of specimen were concentrated at the surface of specimen due to repeated loading under wheel. The cracks were not almost observed at middle part or bottom of specimen.

Fig.1b. shows the 3D image of CT scanner for surface $(2.5 \times 8 \mathrm{~cm})$ of specimen. It shows that the cracks (point of arrow: yellow line) were observed under wheel, which were located at the right end of specimen, which side was measured by ARAMIS system.

Fig.1c. and Fig.1d. show the 2D images of tensile strain and shear strain in specimen SGL-3 for side $(5 \times 8 \mathrm{~cm})$ of specimen, which were measured by ARAMIS. The maximum values of tensile strain under wheel in Fig. 1.c was $3.69 \%$, while the 
maximum value of shear strain under wheel in Fig. 1d. was $3.1 \%$ (see below Table 4). The shape of crack is similar to the shape of the tensile strain at Point $\mathrm{T}$, but the shape of shear strain at Point S was not similar to that of the crack. Then, it seems that cracks were caused by tensile strain rather than shear strain.

Fig.1c. shows the crack points were expressed by yellow areas in this figure. It appears that both crack points (Fig.1a. Fig. 1.b. and Fig. 1.c.) does not completely coincide to each other, because of different image of 2D and 3D, but both points are reasonably coincide to each other.

From those results, it was found that the yellow lines of $0.555 \mathrm{~mm}$ (maximum crack width in this area in Fig. 1a and Fig. 1b) shown by arrows in Fig.1.a.and Fig 1.b correspond to the maximum tensile strains of $3.69 \%$ shown in orange spots (maximum tensile strain at arrow point in Fig. 1c) in the Fig. 1c.. The same relations were also obtained in other specimens.

It suggests that the tensile strain is related with the width of crack in mixture.

\subsubsection{Tensile strain (45 C, 2,400 passes) in the asphalt mixture during the wheel tracking tests}

Fig. 2. shows the distribution of tensile strain and the direction of tensile strain using specimen of SGC-3 (Middle grading curve, asphalt No.3) after 2,400 passes (Stage 9). The small black arrowheads show the direction of tensile strain. The longitudinal color bar (maximum strain: $2.0 \%$ ) in the right side of the figure (Fig. 2.) 
shows the values of tensile strains (\%) in this specimen. The points from Point A to Point E were selected to examine the longitudinal crack using the maximum tensile strains in those points. The points from Point 1 to Point 5 were selected to examine the degree of change in tensile strains from Stage 0 to Stage 9 . The strains at those points (Point 1 to Point 5) showed the maximum values at 50 passes (Stage 2) and it was found that the tensile strains in this specimen increased, together with the increase of tensile strain at those areas. The tensile strain at those points behaves like core which was progressed from those points. But the values of those points were not always the maximum in this specimen.

Fig. 2. also shows the brown areas which are expressed with the direction of strain at the surface and at the bottom of the specimen. The values of maximum tensile strains (brown areas) from Point A to Point E were as follows. Point A: 2.35 \%, Point B: 3.06 \%, Point C: 2.0 \%, Point D: 8.63 \%, Point E: $14.31 \%$. The direction of tensile strain in those areas does not always is a horizontal and it sometimes is a vertical, but the direction of tensile strains at just surface or bottom of specimens are always a horizontal in this study. It seems that the horizontal strain is related to longitudinal crack, and the vertical tensile strain is related to delamination in specimens.

Fig. 3. shows the change of tensile strain of SGC-3 from Stage 0 to Stage 9 at five points (Points 1-Point5). The values of tensile strain from Point 1 to Point 5 at 2,400 passes were as follows. Point 1: $4.98 \%$, Point 2: $2.70 \%$, Point 3: $2.79 \%$, Point 4: $4.36 \%$ and Point 5: $4.92 \%$. It maintains similar appearances of the strain 
distribution under the test in this study. It was found that the points (Point 1-Point 5), which were maximum tensile strains at 50 passes (Stage 2), behave like core, but those values were not always maximum at Stage 9 in this specimen.

It is clear that those tensile strains increased with the increase of stage, but the degree of change at those points were not the same. It means that the tensile strains at those points did not increase with the same speed under repeated loading (Fig. 3.).

Fig. 4. shows the distribution of tensile strains along the three lines (line 0 , line 1, and line 2 in Fig. 2.) across the specimen and at different distances from the specimen surface in the sections of the SGC-3. The positions (lines) of line 0 , line 1 , and line 2 and the tensile strain from Points 1 to Point 5 were selected to examine the tensile strain distribution along the three lines in the cross section of the specimen. The tensile strains were concentrated under the wheel (Fig. 2. and Fig. 4.), but the tensile strain with horizontal arrow at Point C (Fig. 2. and Fig. 5) was $2 \%$ out side the path of the wheel at 2,400 passes (Fig. 5.). It suggests that cracks in the mixture would occur not only under the wheel but also outside the wheel path.

It was reported that all aggregate ( $2 \mathrm{~mm}$ or larger) of the end of specimen $(5 \times 30$ cm) facing the glass in porous mixture (void ratio: $19.9 \%$, content of binder :5.0 \%) remarkably moved ( $1 \mathrm{~mm}$ or more) and rotated (5 degrees or more) under wheel tracking test at high temperature (45 C) [14] and the large strains (500\% or more) occurred around the aggregate in mixture at 600 passes (Stage 6) of wheel under wheel tracking test (45 C), in spite of small rutting (5 mm)[15]. This suggests that tensile 
strains under repeated loading at high temperatures were accumulated with time. Therefore, it appears that the shapes of the spotted tensile strain areas were related with the distribution of accumulated tensile strains in the mixtures.

Fig. 5. shows the distribution of tensile strain and points (Point 1-Point 5) at 45 C at the first pass (Stage 1) of the wheel for the mixture of SGC-3 and the appearance is similar to the tensile strain distributions at $45 \mathrm{C}$ with all the compositions tested here. Points 1 to Point 5 are the same points in Fig.2.. The large tensile strains occurred at just surface and bottom of specimen regardless of the location of wheel. Tensile strain is not always large at the bottom of specimen and distribution of strain was mixed with the tensile strains and compressive strains. The values of tensile strains from Point 1 to Point 5 at the first pass were as follows. Point 1: $0.26 \%$, Point 2: $0.29 \%$, Point 3: $0.16 \%$, Point 4: $0.18 \%$, Point 5: $0.19 \%$. It shows that the tensile strains at Point 1 and Point 2, which are located in the middle part of specimen, are the larger than values of other Points. The tensile strains at the first pass of the wheel (Stage 1 ) in all compositions were approximately $2,000 \times 10^{-6}(0.2 \%)$ to $4,000 \times 10^{-6}$ $(0.4 \%)$ at $45 \mathrm{C}$ (Table 3$)$. Those values were very large which were not expected in this study.

\subsubsection{Shear strain in asphalt mixtures in the wheel tracking test (45 $\mathrm{C}, 2,400$}

\section{passes)}

Fig. 6. shows values of points (Point 6-Point 13), the distribution and the 
direction (arrowheads) of shear strain in SGC-3 at 2,400 passes. Small black arrowheads which were shown in the directions of shear strain, is the same expression in tensile strain in Fig. 2..

Fig. 6. shows that the distribution patterns of shear strains in whole specimen are very similar with the distribution patterns of tensile strains in Fig.2., but the values of both strains were different to each other. Shear strain was relatively small, comparing with that of tensile strain in Fig.2.. The distribution of shear strains is irregular and the shape of distribution in the shear strain from 50 passes (Stage 2) to 2,400 passes (Stage 9) was changed. The shear strain has gradually increased with time for all compositions (Table 4). Table 4 shows that the maximum tensile strain is not almost larger than the maximum shear strain in all compositions, but average tensile strain is always larger than the average shear strain in this study.

Fig.6. shows the distribution of shear strain (warmer colors), compressive shear strains (colder colors) and the direction of shear strain. Shear strain was locally spread under the wheel, but compressive shear strain was also observed under the wheel. The direction of shear strains is diagonal at warmer colors areas (large shear strain) and the direction of shear strain was designated the same direction, in spite of increase of Stage. Fig.1a. shows the cracks concentrated at surface of specimen, but the shape of cracks at surface of specimen was not always vertical. Then, it appears the cracks in Fig. 1a. and Fig. 1 b. were not caused by shear strain.

Fig. 6. shows the values and the direction of shear strains at several points (Point 
6-Point 13) at Stage 9. The values are as follows. Point 6: $0.86 \%$, Point 7: $0.72 \%$, Point 8: $0.80 \%$, Point 9: $0.17 \%$, Point 10: 0.51 \%, Point 11: $0.30 \%$, Point 12: $2.12 \%$, Point 13: $-4.00 \%$. The shear strains in these points are relatively large in surface and bottom of specimen and it is relatively small in the middle part of specimen.

\subsubsection{Strain under the wheel width and strain of the whole specimen}

The distribution of tensile strain and shear strain for the specimen under wheel width (Wheel) and whole specimen (Whole) were examined using five following factors under the wheel load at high temperatures at Stage 9 (2,400 passes) for all specimens. It was investigated for Maximum tensile strain, Average tensile strain, Maximum shear strain, Average shear strain and the ratio of tensile strain of Whole and Wheel.

Table 4 shows the effects of the properties of asphalt and the composition of mixture to the distribution of tensile strain and shear strain using five factors. It shows the maximum tensile strain (Max.), the average tensile strain (Average) in the area (Wheel) under the wheel width $(5 \times 5 \mathrm{~cm})$, and for the whole specimen (Whole)(30 x 5 $\mathrm{cm}$ ), and ratio of Wheel versus Whole specimen (Wheel/Whole) for the average tensile strain for the three different asphalts.

Table 4 also shows the maximum shear strain (Max.), average shear strain (Average) in the area (Wheel) under the wheel width $(5 \times 5 \mathrm{~cm})$, and for the whole specimen (Whole)(30 x $5 \mathrm{~cm})$, in angle in degrees (Deg. and (\%)) for the three 
different asphalts. It showed that distribution of strains depend upon the composition of mixtures and properties of asphalts.

It was concluded that the results in Table 4 and Table 5 (below) show that the distribution of tensile strains were different for the different properties of asphalts, and that the average strain (Wheel; Average) under the wheel width and the average strain (Whole; Average) of the whole specimens was the lowest when the asphalt kai used in the mixture.

The difference between the tensile strain (Wheel; Average) under the wheel in the specimen and the tensile strain of the whole specimen (Whole; Average) was the smallest (Max. strain in Whole: $3.3 \%$, Max. strain in Wheel: $3.3 \%$, Average strain in Whole: $1.35 \%$, Average strain in Wheel: $1.35 \%$ ) in this mixture (SGC, asphalt No. kai). The tensile strain here was the most evenly distributed over the whole specimen. The average strain (Wheel; Average) under the wheel in the specimens of the other two mixtures (SGC-3, SGC-5) was relatively large in this study, showing them to display poorer load distribution qualities.

The ratio (Wheel/Whole) of the average strain within the wheel width and the whole specimen was different from 2.5 to 2.9 (Table 4), when the quality of asphalt was different. Table 4 shows the quality of asphalt affects a remarkable influence on the distribution of the tensile strain, rather than in an effect of the composition.

Table 5 shows the effects of the composition of mixture to the distribution of tensile strain and compressive strain using following factors. It shows the maximum 
tensile strains (Wheel; Max., Whole; Max.), average strains (Wheel; Average, Whole; Average) in the area under the wheel width (Wheel) and in the whole specimen (Whole), and the ratio (Wheel/Whole) of value under the wheel versus the whole for the average tensile strains, and maximum compressive strains (Whole; Max.) for various asphalt (specimen) compositions (45 C, 2,400 passes, Stage 9).

It was concluded that the tensile strain was different for four compositions in Table 5, and the strain (Whole; Average, Wheel; Average) in the SGU composition was relatively small. The ratio (Wheel/Whole) of the average strain in the area under the wheel width in specimen (Wheel) to the whole was from 2.4 to 2.7. Table 5 shows that the smallest average strain (Whole; Average and Wheel; Average) in the whole specimen and within the wheel track in the specimens among the four types of compositions in this study was SGU-3.

It suggests that the quality (load spreadability) in asphalt mixtures was able to evaluated using distribution of strains such as tensile strain and shear strain.

\subsubsection{Maximum tensile strain of point at surface and bottom}

It is an important subject that where does longitudinal crack occur in mixture under wheel tracking test. We assume that it was caused by horizontal tensile strains at surface and bottom under wheel tracking test.

The maximum horizontal tensile strain at surface or bottom of the specimen, and the average tensile strain of the maximum horizontal tensile strains at several points at 
the specimen surface or bottom were rearranged again to compare the values for all specimens. The average tensile strain (Average) at Surface or Bottom of specimens was calculated by computer at several points with maximum horizontal tensile strains at the Surfaces or Bottoms of specimen. The maximum horizontal tensile strain points in Table 3 did not necessarily locate at the specimen Surfaces or Bottoms.

Table 6 shows the values of strains which occurred and the points exceeding below value. They are shown in bold in Table 6 , when the horizontal tensile strain in the asphalt mixture exceeds $3.69 \%$ (described before in 3.1.1).

It was examined that what is the most preferable type of mixture for prevention of crack at high temperature under moving load in this study. Table 6 shows the smallest average tensile strain at the several points of maximum tensile strains at Surfaces or Bottoms of specimen in the mixtures of the four kinds of composition and three types of asphalt was the mixture with the upper grading curve of composition (SGU) using asphalt type No.3. This mixture (SGU-3) can be postulated to be the mixture which makes the occurrence cracks least likely among the mixtures investigated in this study. It seems that the possibility of longitudinal crack can be evaluated using the maximum horizontal tensile strains of points at Surface and Bottom of specimen.

The cause of cracks obtained from above research was summarized as follows. It was summarized that the cracks in Fig.1a. and Fig. 1b. were mainly caused by horizontal tensile strains rather than shear strains, considering with the shape of crack, 
location of crack, distribution of strain, the direction of strain, the value of strain and location of strain.

\section{Conclusions}

The conclusions of this study may be summarized as follows.

1. The cracks with different width like a net type in asphalt mixtures were observed at near surface of specimen after wheel tracking test at high temperatures.

2. The cracks in mixture under wheel tracking test at high temperature were mainly caused by tensile strains, and large horizontal tensile strains were sometimes located at surface or bottom of specimen under the wheel.

3. Some tensile strains reached the maximum value at 50 passes (Stage 2) of wheel and gradually increased with time, but the degree of change at those values was different.

4. ARAMIS system and three dimensional crack analyses were very useful for analyses of cracks in mixtures. The quality in mixtures after wheel tracking test can be evaluated by those methods.

5. The specimens with small rutting ( $1 \mathrm{~mm}$ or smaller) which were used in this study, were caused to large tensile strains due to wheel load. It appears that the relationship between tensile strains (3.69\%) and width of crack $(0.555 \mathrm{~mm})$ in asphalt mixtures exists.

6. The distribution of tensile strains at first pass (Stage 1) under moving load at high 
temperature was almost uniform, but tensile strains were accumulated at several points with time, together with the widening of width in tensile strains, and large horizontal tensile strains also occurred outside the direct path of the wheel.

7. The maximum tensile strain at the first pass (Stage 1) of the wheel at $45 \mathrm{C}$ for all compositions varied from approximately $2,000 \times 10^{-6}(0.2 \%)$ to $4,000 \times 10^{-6}(0.4 \%)$ and those were not located at the bottom of specimen under the wheel.

8. Load spreadability in asphalt mixtures under wheel tracking test can be evaluated using the distribution of strains under wheel tracking test.

We are now preparing experiments with new multi-layered specimens using techniques similar to the indoor experiments reported here, these experiments will be conducted in the field and based on actual in-situ temperature distributions. This will make it possible to evaluate the quality of each layer in pavements and offers the potential for developing more durable pavements with longer service lives.

\section{Acknowledgement}

The authors wish to thank Corporation NIPPO Hokkaido Branch, Obayashi Road LtD., for their technical support.

\section{References}

[1] Molenaar A. A. A., Fatigue and Reflection Cracking Due to Traffic Roads, Proc. Ass. 
of Asphalt Paving Technologies, 1984; 54: 454-496.

[2] Matsuno S. and Nishizawa T., Longitudinal Surface Cracking of Flexible Pavement, Proc. of Paving in Cold Area Mini-Workshop Canada/Japan Science and Technology Consultations,1984; 779-786.

[3] Hugo, F. and Kennedy, T. W., Surface cracking of asphalt mixtures in Southern Africa, Proc. Ass. of Asphalt Paving Technologists,1985; 54: 454-496.

[4] Gerritsen, A. H., van Gurp, C. A. P. M., van der Heide, J. P. L., Molenaar, A. A. A. and Pronk, A. C., Prediction and Prevention of Surface Cracking in Asphaltic Pavements, Proceedings, $6^{\text {th }}$ International Conference Structural Design of Asphalt Pavements, 1987; 378-391.

[5] Leslie Ann Myers, Reynaldo Roque, Bjorn Birgisson, Propagation Mechanisms for Surface-Initiated Longitudinal Wheelpass Cracks, Transportation Research Board of the National Academies, 2001; 1778: 113-122.

[6] A. Moriyoshi, H. Harada and S. Takano, Stress analysis of longitudinal cracking in the wheel paths of bituminous pavements at high temperature, Performance of Bituminous and Hydraulic Materials in Pavement, Proc. of the Fourth European Symposium, 2002.

[7] H. Ishikawa, S. Takahashi, T. Nakai and A. Moriyoshi, Innovation in porous asphalt quality control for cold regions on the AYABE-MIYAZU Road in Japan, Proc. of the 3rd European Symposium on performance and durability of bituminous materials and hydraulic stabilized composites,1999; 653-662. 
[8] Japan Road Association, Manual for test method of Pavement, 2010; Part III, [3]-039.

[9] Abd Alla E. M., Moriyoshi A., Partl M. N., Takahashi K., Kondo T., Tomoto T., New wheel tracking test to analyze movements of aggregates in multi-layered asphalt specimens, Journal of the Japan Petroleum Institute, 2006; 49, (5): 274-279.

[10] Timothy Schmidt and John Tyson, Full-field dynamic displacement and strain measurement using advanced 3D image correlation photogrammetry, Experimental Techniques, Part I :May/June 2003; 27,(3): 47-50, Part II : July/Aug.27, (4): 44-47.

[11] S. Taniguchi, I. Nishizaki and A. Moriyoshi, A study of longitudinal cracking in asphalt pavement using CT scanner, Road Materials and Pavement Design, 2008; 9, (3): 549-558.

[12] T. Tomoto, A. Moriyoshi : Relation between wheel tracking test, bending test, CT scan analysis for different mixtures after wheel tracking test at high temperatures, 5as JORNADAS INTERNACIONALES DEL ASFALTO, 2006.

[13] T. Tomoto, A. Moriyoshi, Evaluation of Damage to Asphalt Pavement using a Micro-focus CT Scanner and Three-dimensional Crack Analysis, Road Materials and Pavement Design, 2009; 10, (3): 519-544.

[14] T. Kondo, A. Moriyoshi, T. Yoshida, S. Takahashi, Movement characteristics of aggregate in asphalt mixtures during the wheel tracking test, Journal of the Japan 
Petroleum Institute, 2003; 46, (3): 172-180.

[15] T. Kondo, A. Moriyoshi, T. Yoshida, S. Takahashi, Crack formation in asphalt mixtures in the wheel tracking test at high temperature, Journal of the Japan Petroleum Institute, 2004; 47, (2): 90-99. 


\section{Figure Captions}

Fig. 1. 3D image of crack and 2D image of tensile strain in a SGL-3 specimen (Lower grading curve, asphalt No.3)(45 C, 2,400 passes, Stage 9)

Fig. 2. Tensile strain distribution and tensile strains at various points in a SGC-3 specimen $(2,400$ passes, Stage 9$)$, (Line 0: $-1.25 \mathrm{~cm}$ from the top surface, Line 1: $-2.5 \mathrm{~cm}$, Line 2: $-3.75 \mathrm{~cm})$

Fig. 3. Horizontal tensile strains at the points (1 to 5) marked in Fig. 1., at the different stages of the experiment (SGC-3, Stages 0 to 9)

Fig. 4. Tensile strain distribution and tensile strains at points (1 to 5) in a SGC-3 specimen (45 C, first pass, Stage 1)

Fig. 5. Tensile strain distribution along the three lines across the specimens (Fig. 2) after 2,400 passes of the wheel (for the SGC-3 specimen, Stage 9). Line 0: $-1.25 \mathrm{~cm}$, Line 1:-2.5 cm, Line 2: $-3.75 \mathrm{~cm}$ (distances here are the depth below the top of the specimen)

Fig. 6. Shear strain distribution and shear strains at points (6 to 13) in SGC-3 (45 C, 2,400 passes, Stage 9)

\section{Table Captions}

Table 1 The main characteristics of the asphalts

Table 2 Compositions of mixtures 
Table 3 One pass strain (tensile) within the width of the wheel (45 C, first pass of wheel, Stage 1)

Table 4 The maximum tensile strain (Whole; Max., Wheel; Max.), average tensile strain (Whole; Average, Wheel; Average) in the area under the wheel width (Wheel: $5 \mathrm{x}$ $5 \mathrm{~cm}$ ) and for the whole specimen (Whole: $30 \times 5 \mathrm{~cm}$ ), and average tensile strain ratio of wheel versus Whole (Wheel/Whole), and the maximum shear strain (Whole; Max., Wheel; Max.), average shear strain (Whole; Average, Wheel; Average) for the whole specimen in (angle in degrees: Deg.) and (\%) for three different asphalts.

Table 5 Maximum tensile strain (Whole; Max., Wheel; Max.), average tensile strain (Whole; Average, Wheel; Average) in the area under the wheel width (Wheel) and for the whole specimen (Whole), and the ratio (Wheel/Whole) of wheel versus whole for average tensile strain, and maximum compressive strain (Whole, Wheel) for the whole specimen with different asphalt compositions (45 C, 2,400 passes, Stage 9)

Table 6 Maximum tensile strain (\%) at the Surface or Bottom of specimens, and the average tensile strain (\%) of maximum tensile strain at several points of the Surface or Bottom of specimens (45 C, 2,400 passes, Stage 9) 



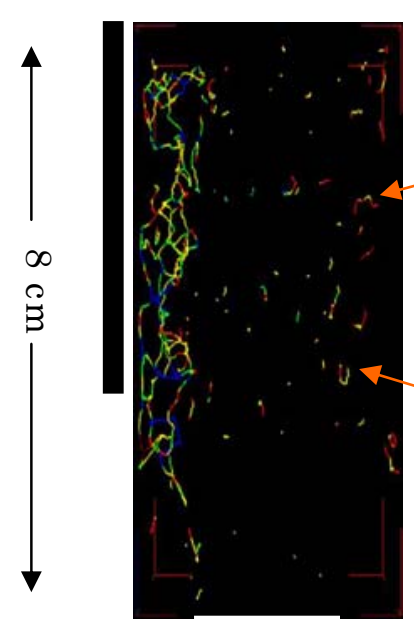

$5 \mathrm{c} \mathrm{m}$

Crack (Side) in 3D Image

Fig. 1a.

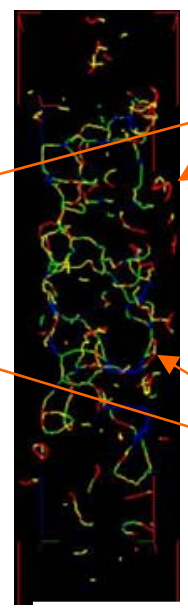

$2.5 \mathrm{c} \mathrm{m}$

Crack (Surface) in 3D Image

Fig. 1b.

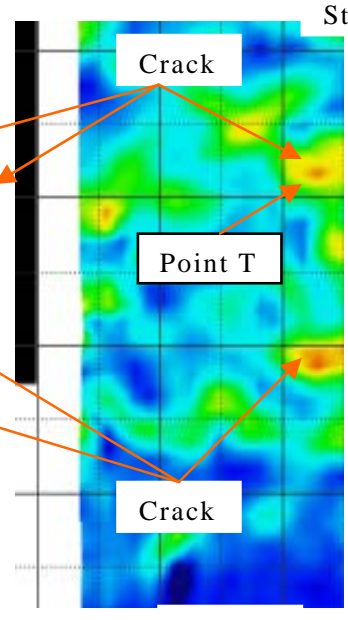

$5 \mathrm{~cm}$

Tensile Strain(Side) in 2D Image

Fig. 1c.

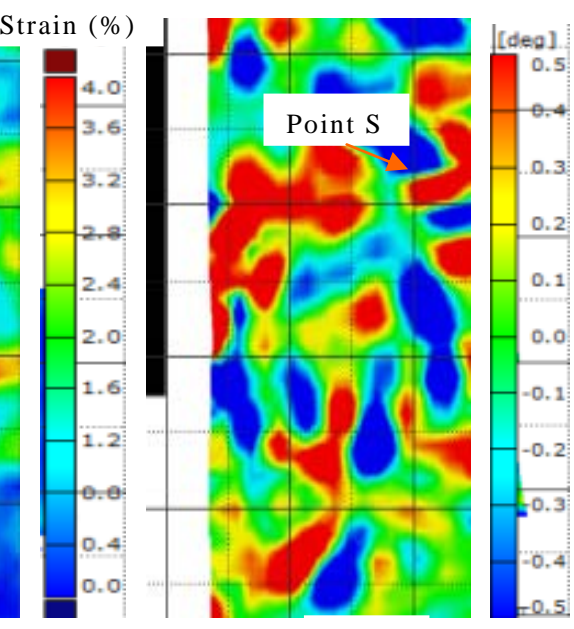

$5 \mathrm{~cm}$

Shear Strain(Side)

in 2D Image

Fig.1d.

Fig. 1. 3D image of crack and 2D image of tensile strain in a SGL-3 specimen (Lower grading curve, asphalt No.3)(45 C, 2,400 passes, Stage 9)

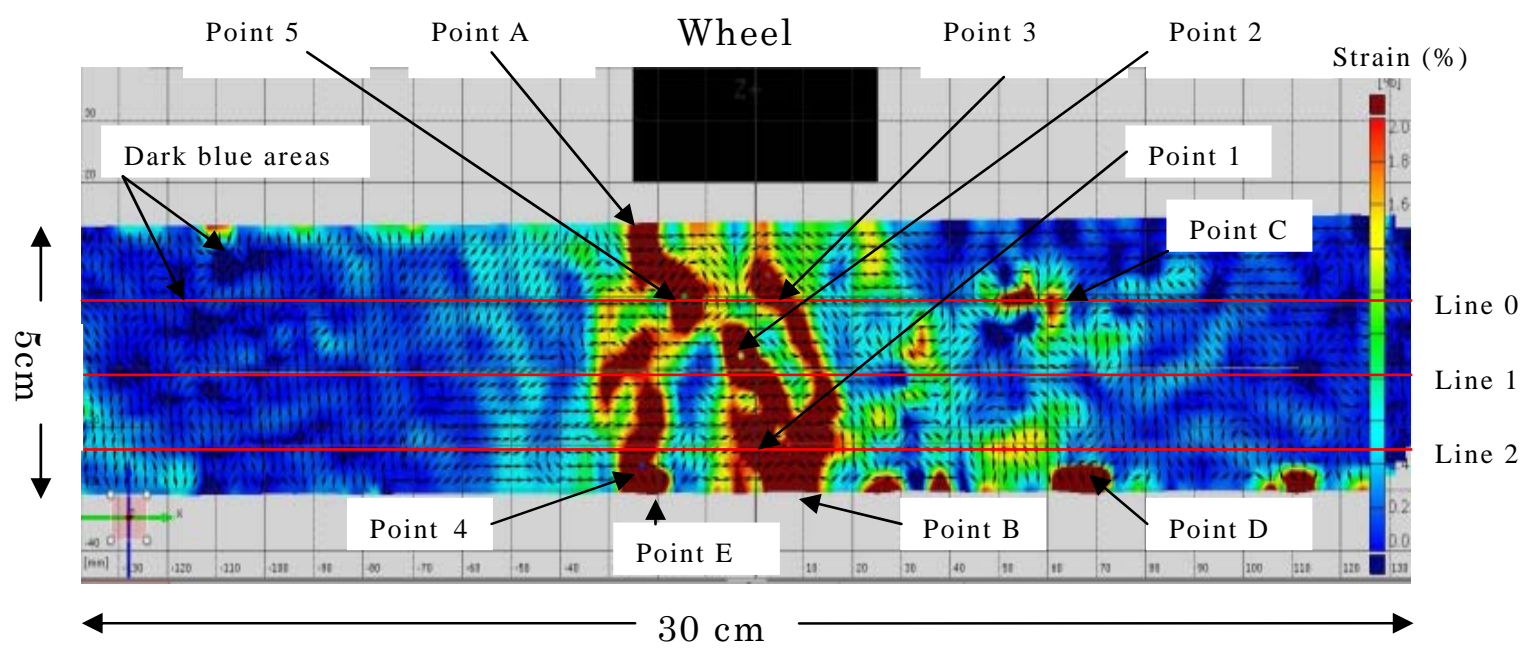

Fig. 2. Tensile strain distribution and tensile strains at various points in a SGC-3 specimen (2,400 passes, Stage 9), (Line 0: $-1.25 \mathrm{~cm}$ from the top surface, Line 
1: $-2.5 \mathrm{~cm}$, Line 2: $-3.75 \mathrm{~cm})$

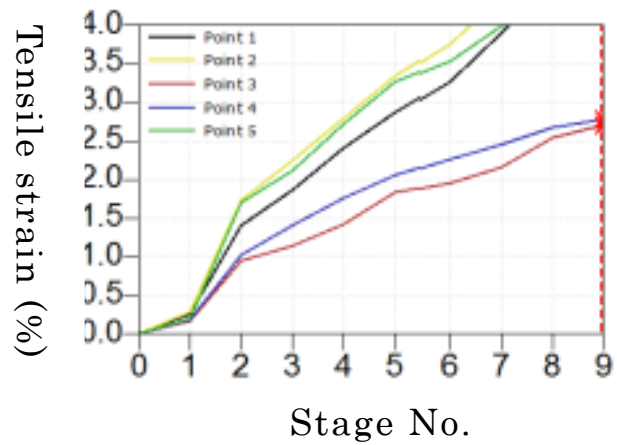

Fig. 3. Tensile strains at the points (Point 1 to Point 5) marked in Fig. 2., at the different stages of the experiment (SGC-3, Stages 0 to 9)

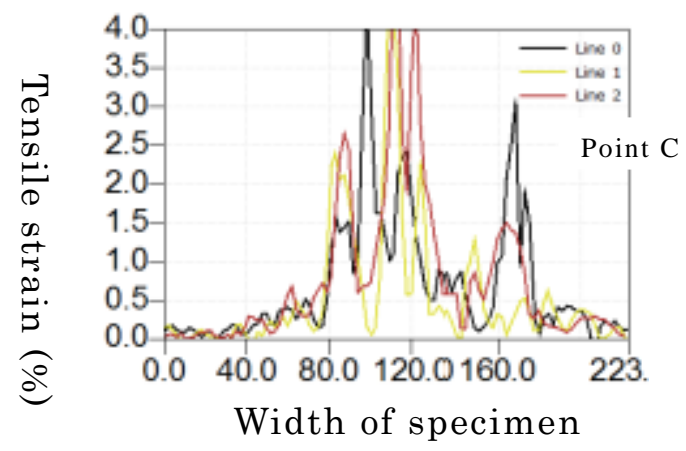

Fig. 4. Tensile strain distribution along the three lines across the specimens (Fig. 2) after 2,400 passes of the wheel (for the SGC-3 specimen, Stage 9). Line 0: $-1.25 \mathrm{~cm}$, 
Line 1:-2.5 cm, Line 2: $-3.75 \mathrm{~cm}$ (distances here are the depth below the top of the specimen)

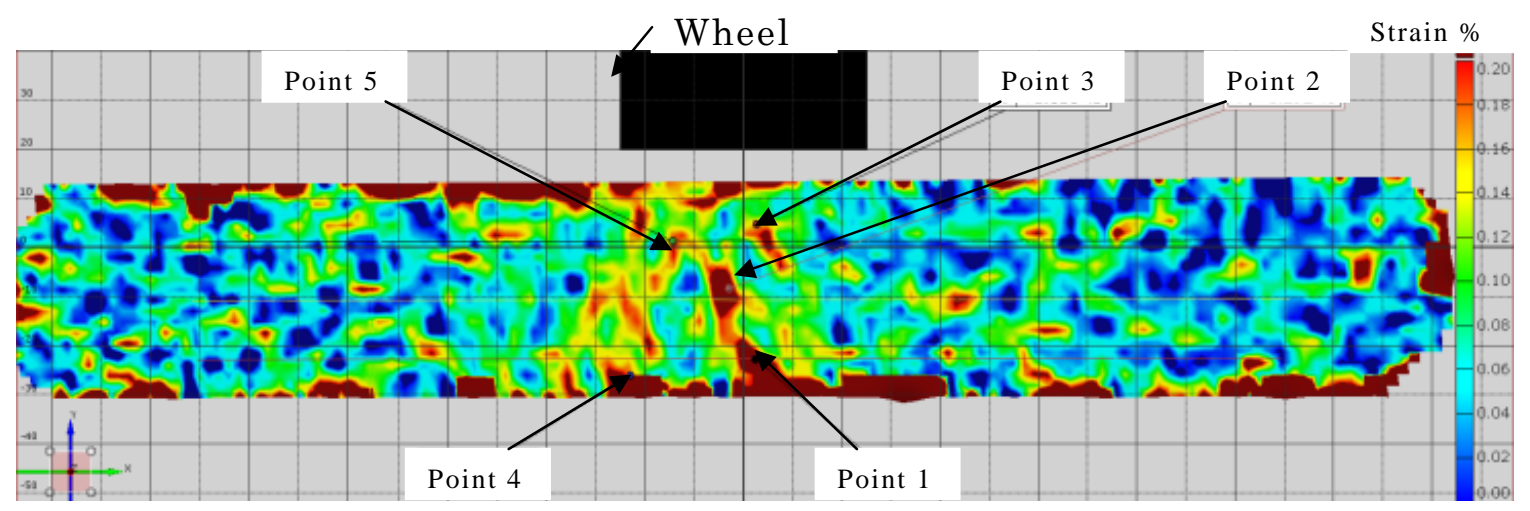

Fig. 5. Tensile strain distribution and tensile strains at points (Point 1 to Point 5) in a SGC-3 specimen (45 C, first pass, Stage 1)

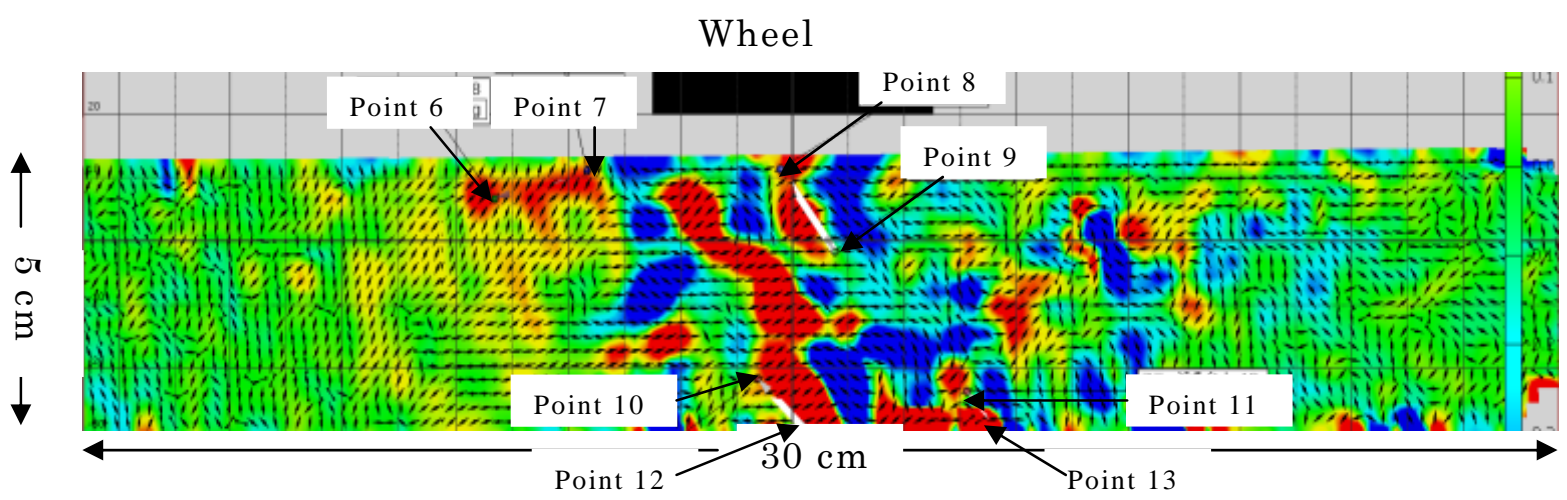

Fig. 6. Shear strain distribution and shear strains at points (Point 6 to Point 13) in SGC-3 (45 C, 2,400 passes, Stage 9) 
Table 1 The main characteristics of the asphalts

\begin{tabular}{lrrrrr}
\hline Asphalt Type & $\begin{array}{c}\text { Penetration } \\
(25 \text { C) }\end{array}$ & $\begin{array}{l}\text { Softening } \\
\text { Point (C ) }\end{array}$ & $\begin{array}{l}\text { Ductility } \\
(15 \text { C) }\end{array}$ & \multicolumn{2}{c}{$\begin{array}{l}\text { Fraass Breaking } \\
\text { Point (C ) }\end{array}$} \\
\hline Modified Type kai* & 56 & 68.5 & 71 & -18 \\
Modified Type No.3 & 65 & 112.5 & $100+$ & -19 \\
Modified Type No.5 & 59 & 117 & 80 & -24 \\
\hline
\end{tabular}

*: Modified Type kai: It is named modified type $\mathbb{I}$ in Japan

Table 2 Composition of mixtures

\begin{tabular}{lrcrr}
\hline $\begin{array}{l}\text { Sieve } \begin{array}{l}\text { Opening } \\
(\%)\end{array} \\
\text { (Upper) }\end{array}$ & \multicolumn{1}{c}{$\begin{array}{l}\text { SGC } \\
\text { (Mean) } \\
\text { Gap type coarse }\end{array}$} & $\begin{array}{l}\text { SGL } \\
\text { (Lower) }\end{array}$ & $\begin{array}{c}\text { Hybrid Type } \\
\text { (K II ) }\end{array}$ \\
\hline $19 \mathrm{~mm}$ & 100 & 100 & 100 & 100 \\
$13.2 \mathrm{~mm}$ & 98.6 & 98.5 & 98.5 & 98.5 \\
$9.5 \mathrm{~mm}$ & 83.3 & 82.8 & 81.7 & 82.4 \\
$4.75 \mathrm{~mm}$ & 38.3 & 36.3 & 32.6 & 35 \\
$2.36 \mathrm{~mm}$ & 30.8 & 27.3 & 24.4 & 26.4 \\
$0.6 \mathrm{~mm}$ & 19.8 & 17.7 & 16.2 & 18.7 \\
$0.3 \mathrm{~mm}$ & 14.5 & 13.3 & 12.3 & 15.3 \\
$0.15 \mathrm{~mm}$ & 9.4 & 8.9 & 8.6 & 12 \\
$0.075 \mathrm{~mm}$ & 7.7 & 7.4 & 7.3 & 1.5 \\
\hline Asphalt & 4.6 & 5.2 & 5.5 & 5.6 \\
Content(\%) & & & & \\
\hline
\end{tabular}

Table 3 One pass strain (tensile) within the width of the wheel and void ratio (45 C, first pass of wheel at Stage 1)

\begin{tabular}{|c|c|c|c|c|}
\hline $\begin{array}{l}\text { Specimen } \\
\text { Composition }\end{array}$ & Asphalt No. & $\begin{array}{l}\text { Max. strain } \\
(\%)\end{array}$ & $\begin{array}{l}\text { Max. strain position } \\
\text { in the specimen }\end{array}$ & $\begin{array}{c}\text { Void ratio } \\
(\%)\end{array}$ \\
\hline K I I & No.3 & 0.4 & Bottom & 3.7 \\
\hline SGL & No.3 & 0.18 & Middle & 5.5 \\
\hline SGC & No.3 & 0.29 & Middle & 5.5 \\
\hline SGU & No.3 & 0.36 & Middle & 5.5 \\
\hline SGC & No.kai & 0.17 & Middle & 5.5 \\
\hline SGC & No.5 & 0.28 & Bottom & 5.5 \\
\hline
\end{tabular}


Table 4 The effects of properties of asphalt and composition of mixture on the distribution of tensile strain and shear strain.

\begin{tabular}{|c|c|c|c|c|c|c|c|}
\hline \multicolumn{3}{|c|}{$\begin{array}{l}\text { Composition } \\
\text { Asphalt No. }\end{array}$} & $\begin{array}{c}\text { Max. } \\
\text { (Tensil€ } \\
(\%) \\
\end{array}$ & $\begin{array}{l}\text { Average } \\
\text { strain) } \\
\text { (Av }\end{array}$ & $\begin{array}{l}\text { Ratio of } \\
\text { Wheel/Whol } \\
\text { verage strain) }\end{array}$ & \multicolumn{2}{|c|}{$\begin{array}{l}\text { Max. Average } \\
\text { (Shear) } \\
\text { Deg. and (\%) }\end{array}$} \\
\hline \multirow[t]{2}{*}{ SGC } & No.3 & Whole & 24 & 0.6 & & 12.17(21.6) & $\mathbf{0 . 0 2}(0.03)$ \\
\hline & & Wheel & 24 & 1.64 & 2.7 & 12.17(21.6) & $\mathbf{0 . 1 2}(0.2)$ \\
\hline \multirow[t]{2}{*}{ SGC } & No.5 & Whole & 19.1 & 0.4 & & 3.14(5.5) & $\mathbf{0 . 0}(0.0)$ \\
\hline & & Wheel & 15.5 & 1.17 & 2.9 & $3.14(5.5)$ & $\mathbf{0 . 1 6}(0.28)$ \\
\hline \multirow[t]{2}{*}{ SGC } & No.kai & Whole & 3.3 & 0.36 & & $1.35(2.4)$ & $\mathbf{- 0 . 0 2}(-0.03)$ \\
\hline & & Wheel & 3.3 & 0.89 & 2.5 & $1.35(2.4)$ & $\mathbf{0 . 4 3}(0.75)$ \\
\hline \multirow[t]{2}{*}{$\mathrm{K}$ II } & No.3 & Whole & 10.7 & 0.56 & & 9.81(17.3) & $-\mathbf{0 . 0 5}(0.08)$ \\
\hline & & Wheel & 10.7 & 1.34 & 2.4 & 9.81(17.3) & $\mathbf{- 0 . 0 2}(-0.03)$ \\
\hline \multirow[t]{2}{*}{ SGL } & No.3 & Whole & 3.69 & 0.52 & & $2.70(4.7)$ & $\mathbf{- 0 . 0 2}(-0.03)$ \\
\hline & & Wheel & 3.69 & 1.29 & 2.5 & $1.79(3.1)$ & $\mathbf{0 . 0 3}(0.05)$ \\
\hline \multirow[t]{2}{*}{ SGU } & No.3 & Whole & 4.7 & 0.44 & & 15.37(27.5) & $\mathbf{0 . 0 1}(0.02)$ \\
\hline & & Wheel & 5.31 & 1.15 & 2.6 & $5.86(10.3)$ & $\mathbf{0 . 1 1}(0.2)$ \\
\hline
\end{tabular}

Table 5 The effects of composition of mixture on distribution of tensile strain and compressive strain

\begin{tabular}{|c|c|c|c|c|c|c|}
\hline \multicolumn{3}{|c|}{$\begin{array}{l}\text { Composition } \\
\text { Asphalt No. }\end{array}$} & \multicolumn{2}{|c|}{$\begin{array}{l}\begin{array}{l}\text { Max. Average } \\
\text { (Tensile strain) } \\
(\%)\end{array} \\
\end{array}$} & \multirow[t]{2}{*}{$\begin{array}{l}\text { Ratio of } \\
\text { Wheel/Whole } \\
\text { (Average strain) }\end{array}$} & \multirow{2}{*}{$\begin{array}{c}\text { Max. } \\
\text { (Compressive strain) } \\
(\%) \\
-1.74\end{array}$} \\
\hline K II & No.3 & Whole & 10.7 & 0.56 & & \\
\hline & & Wheel & 10.7 & 1.34 & 2.4 & -0.3 \\
\hline \multirow{2}{*}{ SGL } & No.3 & Whole & 3.69 & 0.52 & & -0.461 \\
\hline & & Wheel & 3.69 & 1.29 & 2.5 & -0.004 \\
\hline \multirow[t]{2}{*}{ SGC } & No.3 & Whole & 24 & 0.6 & & -0.896 \\
\hline & & Wheel & 24 & 1.64 & 2.7 & -0.011 \\
\hline \multirow[t]{2}{*}{ SGU } & No.3 & Whole & 37.1 & 0.44 & & -0.176 \\
\hline & & Wheel & 5.3 & 1.15 & 2.6 & -0.009 \\
\hline
\end{tabular}

K II : Hybrid type, SGL: Lower grading curve, SGC: Middle grading curve, SGU: Upper grading curve 
Table 6 Maximum tensile strain (\%) at the Surface or Bottom of specimens, and the average tensile strain (\%) of maximum tensile strain at several points of Surface or Bottom of specimens (45 C,2,400 passes, Stage 9)

\begin{tabular}{lcrc}
\hline Specimen & Asphalt No. & Max. (\%) Average (\%) \\
\hline K II & No.3 & & \\
Surface & & $\mathbf{6 . 5 8}$ & 3.02 \\
Bottom & & 3.49 & 2.49 \\
SGC & No.3 & & \\
Surface & & 2.31 & \\
$\quad$ Bottom & & $\mathbf{1 4 . 3 1}$ & 8.63 \\
SGC & No.5 & & \\
Surface & & 3.67 & \\
Bottom & & $\mathbf{1 1 . 8 3}$ & $\mathbf{7 . 3 9}$ \\
SGL & No.3 & & \\
Surface & & 2.35 & 1.87 \\
Bottom & & 3.03 & 2.96 \\
SGU & No.3 & & \\
Surface & & 0 & \\
Bottom & & 2.88 & 2.72 \\
\hline
\end{tabular}

